\title{
Delirium Due to a General Medical Condition
}

National Cancer Institute

\section{Source}

National Cancer Institute. Delirium Due to a General Medical Condition. NCI Thesaurus.

Code C92639.

A disorder characterized by the acute and sudden development of changes in attention, memory, language and/or perception that can be etiologically linked to the direct physiological consequences of a general medical condition. 